are everywhere and at all times present in the atmosphere. Mr. Tomlinson has shown experimentally that a crystal of the salt properly treated can be inactive in a solution of sodic sulphate. ${ }^{*}$

The following experiments show that an atmosphere presumably saturated with the salt may be inactive without any precautions whatever:-

7. Three solutions of sodic sulphate were prepared; a glass rod was dipped in melted tallow and left to cool for five minutes in a bottle of the salt, without touching the salt or the sides of the bottle. Then the three solutions were successively touched with the rod; inactive in all. Rod replaced in the bottle for ten m:ore minutes; then all three again touched. The third crystal. lised after a minute or two. Rod replaced for fifteen minutes; active only in the second; replaced for fifteen minutes, active in the last. Thus this greasy rod was inactive in one of the solutions after an exposure of thirty minutes, and after being six times dipped in solutions of the salt.

8. An open test tube, containing a strong solution of sodic sulphate, remained supersaturated for a week suspended in the same large bottle of the salt. The bottle was frequently moved withont producing any effect. On removing the cork, the solution crystallised instantiy.

On the whole I am afraid we must for the present fall back npon that refuge for the destitute, "Catalytic action."

Birmingham

J. G. Grenfell

Derivation of the Term "Horse-Chestnut"

The explanation of the above name by Mr. E. A. Connell in your last issue, though ingenious, is not, I think, the true one. In a work entitled "Etymons of English Words," by John Thomson, Edinburgh, I 826, the term is explained thus:- "HorseChestnut. The harsh-chestnut; but the F. and the Swedes have translated it as horse." Following this he gives in support of horse, being the corruption of harsh, horse-faced, harsh-faced, hard-featured, horse-radish, harsh-radish ;" and harsh, rough, sour, austere, grating, S. harsk, T. harsch, D. harsk. So that, accepting this explanation, harsh.chestnut is the more scientific term.

Trehelig, :Llangadock, Carmarthenshire, July i6 J. JEREMIAH

\section{Ozone and Thunderstorms}

IN reference to the production of ozone it may interest your readers to know that the quantity developed here has been unusually great during the last few days. On Sunday evening, during the electrical agitation that occurred and ended in a slight discharge, accompanied by heavy rain, we had the highest reading. Mr. Burrows' test paper registered 9, and was almost black. This observation was taken at Io A.M. During the period of this development the air was very moist. Last evening and this morning have caused the ozonometer to register 7 , and this is above the average. To-day, Tuesday, the hygrometer indicated the point of saturation. I may add that old Gilbert White's remark as to activity of swifts during thundery weather has been greatly confirmed. They have kept up an almost incessant screaming during the last few days.

Great Malvern, August 2

SAMUel BARBER

\section{The Sun's Corona}

A LETTER of mine, addressed to you a fortnight since, has, I fear, miscarried. It had special claim to admission as complaining of an editorial remark.

I now renew my objection to the editorial note upon my letter referring to Professor Pritchard's critique on my "Other Worlds." As an uncourteous comment upon a passage in which I had paid a high but not undeserved compliment to Mr. Lockyer, I had just reason to be surprised at its appearance.

First, because my account of Mr. Lockyer's views respecting

* It would seem from the experiments of Dr. L. C. de Coppet (which do not appear to be as well known as they deserve) that the treatment adopted by Mr. Tominson for rendering the sodic sulphate inactive really changes phate may be prepared by dissolving the anhydrous salt in cold water: and phate may be prepared by dissolving the anhydrous salt in cold water; and phate obtained by the efflorescence of the crystals with ten molecules of phate obtained by the efflorescence of the crystals with ten molecules of superior to $33^{\circ}$ or $34^{\circ}$; for the contact of a particle of the efforesced sulphate always causes the crystallisation of a supersaturated solution of this salt, whereas anhydrous sodic sulphate heated above $33^{\circ}$ does not necessarily deternaine the crystallisation."--Bull. Soc. Vaud. Sc. Nat. X., p. $\times 5$ r.

[These experiments render it probable that the so-called supersalurated solutions really contain the anhydrous salt in a state of unstable equilibrium, only requiring a disturbance to cause it to assimilate water, and thus produce only requiring a disturbance to ta
a less soluble compound.-ED. the corona agrees in all essential points with that given in the note, whereas the contrary is implied.

Secondly, because I have not nis-stated Dr. Gould's evidence, though forced to interpret it otherwise than he does.

Thirdly, because my whole reasoning on the corona has been founded on evidence, and is therefore unjustly described in the note as "evolved from the depths of my moral conscious. ness" (an old witticism, which, however, would have borne repeating had it been to the point.) *

To the personalities in the note, as to the reference to my age, and so on, I make no objection whatever, caring only to notice what seems worthy of notice.

Let me add, however, my protest against a mode of speaking which implies that observers only are to be considered as astronomical workers. Not on my own account, but on behalf of a long list of honoured names, I oppose the assumption that the careful study of observations (whether those observations have been made by others or not) is not to be regarded as work. If observers claim with pride such names as Herelius, Galileo; Ty. cho Brahe, Bradley, and many more, the advocates of thoughtful theorising may point no less confidently to Copernicus, to Kepler, and to Newton, and in our own times to Adams and Leverrier. Those who, like the Herschels, have been able to work successfully in both ways, are few indeed in number.

Observations will never be so little useful as when the attempt to atilise them is discouraged.

P.S. - Mr. Lockyer seems not to b to have proved respecting the corona is accepted by me as proved, and forms an essential part of my theory. I am as well satis. fied as he can be (and on the same grounds) that the corona is not a solar atmosphere.

\section{VON GRAEFE}

$S$ PEAKING of the loss of Von Graefe, whose death, at the age of forty-one, we reported last week, the Revue des Cours Scientifiques remarks that Germany has sustained a loss equal at least to the loss of a battle. Von Graefe's death was the sequel of a long consumption, during which he neither diminished his work nor took ordinary precautions. His grand discovery of the cure for Glaucoma was made when he was only twenty-six years old. The British Medical fournal thus sums up his professional worth :-

In him the world loses its foremost opthalmologist, one whose brilliant originality was equalled only by his steady industry. Not only was Graefe great in the practice of his profession, but as a teacher his influence was almost unbounded. Although comparatively young himself, he had taught almost all the present school of ophthalmic surgeons. His introduction of iridectomy was, without doubt, the greatest step in the operative surgery of the eye since the introduction of operations for the cure of cataract. Probably, there are now living some thousands in the possession of sight, who but for him would have been in darkness. It is one of those gains which is complete in itself, permanent, and beyond the reach of scepticism. It is priceless. Graefe was an untiring observer, and never allowed his pressing engagements to interfere with the record of his vast experience for the good of others. Although he had done a vast amount of other work, still, however, his discovery of iridectomy shines with such pre-eminent lustre that the inscription, "He cured Glaucoma,"

would be by no means inappropriate. As a man, Graefe was everything that is admirable, and secured the love of all who knew him. He was open, generous, unostentatious, eager both. to give and receive knowledge. His personal appearance was as remarkable as the qualities of his mind. The Wiener Medizen Wochensshrift, in announcing Graefe's' death, says : "German science loses in him one of her greatest celebrities, and suffering humanity one of its greatest benefactors. With Gracfe, a combination of geniality, erudition, self-devotion, energy, and amiability, such as is rarely found in one man, has descended into the grave. His name will ever remain most prominently connected with the history of ophthalmic surgery."

* Still holding to our comments we gladly state that they were not written in the spirit in which Mr. Proctor has read them. He is known to all as an astronomical worker, and our objection to his mathematical result was that it was'based upon data among which the principal point at issue was ac* cepted as proved. $-\mathrm{ED}$. 